\title{
Combates na história atlântica: a historiografia de Joseph E. Inikori*
}

\author{
Battles in Atlantic History: the Historiography of Joseph E. Inikori
}

\author{
Gustavo Acioli Lopes \\ aciolilopes@yahoo.com.br \\ Professor adjunto \\ Universidade Federal da Paraíba \\ Av. Júlia Freire, 1555/2102 - Expedicionários \\ 58041-000 - João Pessoa - PB \\ Brasil
}

\begin{abstract}
Resumo
O presente artigo aborda a historiografia do nigeriano Joseph E. Inikori, destacando sua análise de três temas clássicos da história atlântica moderna: o aspecto quantitativo do tráfico transatlântico de escravos, o impacto do tráfico de escravos na África e a relação entre o capitalismo e a escravidão moderna. Apresentam-se os seus argumentos em contraposição a outras abordagens que aqui denominamos "revisionistas", de forma a ressaltar os principais pontos de discordância que têm marcado os debates no campo referido e a posição de Inikori nele. Argumenta-se, enfim, que suas análises constituem uma tese mais ampla sobre a formação do mundo atlântico desde o séc. XVI até o advento da Revolução Industrial.
\end{abstract}

Palavras-chave

Joseph E. Inikori; Historiografia; História atlântica.

\begin{abstract}
This article investigates Joseph E. Inikori's historical writings, highlighting his approach to three classical subjects of modern Atlantic history: the quantitative features of the transatlantic slave trade, its consequences on African societies, and the relation between capitalism and modern slavery. It introduces Inikori's approaches as opposed to other perspectives, here identified as "revisionist", in order to underscore the major points of disagreement that have been pervasive in this field of scholarly debates, as well as Inikori's standpoint in them. Finally, the article argues that Inikori's analyses comprise an encompassing thesis on the making of Atlantic world from the sixteenth century to the Industrial Revolution.
\end{abstract}

Keywords

Joseph E. Inikori; Historiography; Atlantic history.

Recebido em: 5/8/2012

Aprovado em: 13/10/2012

\footnotetext{
* Gostaria de agradecer ao prof. Maximiliano M. Menz (UNIFESP), que leu a primeira versão do artigo e fez sugestões importantes; e ao mestrando Diego Cambraia (FFLCH/USP), pela ajuda na obtenção de material bibliográfico. Devo mencionar os pareceristas anônimos, cujas observações me permitiram tornar mais precisos alguns trechos do texto e corrigir informações.
} 
Joseph E. Inikori se formou na Universidade de Ibadan, na Nigéria, onde concluiu o seu doutoramento nos anos $1970 .{ }^{1}$ Em seguida, ele passou a lecionar em outra destacada universidade nigeriana, a Ahmadu Bello, onde foi professor por 15 anos (1974-1988). Ele fez parte do que se tornou conhecido como a "Escola de História de Ibadan", ou seja, um conjunto de historiadores africanos que renovaram os estudos sobre a África, em particular das sociedades que compuseram a Nigéria quando de sua independência, desde os anos 1950, a partir da fundação da Universidade de Ibadan (FALOLA 2006; LOVEJOY 1985, p. 203). Esse grupo ligado à Universidade de Ibadan privilegiou a pesquisa e a narrativa de eventos políticos do período anterior à conquista europeia no séc. XIX, pois visava alicerçar a unidade nacional numa narrativa do passado que apontasse para uma unidade prévia e para uma continuidade política. No entanto, desde o princípio de sua trajetória acadêmica, Inikori foi bem além do foco temático do grupo, ao tratar de questões socioeconômicas que transcendiam a história da Nigéria (LOVEJOY 1985, p. 198-199). Posteriormente, Inikori tornou-se professor da Universidade de Rochester (Nova Iorque), na qual permanece ainda hoje.

A obra do autor nigeriano é pouco divulgada entre os pesquisadores brasileiros, não sendo muito citada, mesmo entre os especialistas dos temas afins a sua produção. No entanto, Inikori tem produzido textos relevantes, com repercussões entre os pares, desde os anos 1970, dando uma contribuição importante aos debates acerca da história econômica moderna e contemporânea do mundo atlântico. ${ }^{2}$ Da variedade de artigos, capítulos e livros em que apresentou suas pesquisas e argumentos, pode-se estabelecer uma linha de abordagem que marca boa parte de sua produção: a crítica às teses revisionistas. ${ }^{3}$

Os argumentos do autor são apresentados, aqui, de acordo com três temas que ele vem pesquisando e debatendo ao longo das últimas quatro décadas: a) o aspecto quantitativo do tráfico transatlântico de escravos (pelos ingleses e por todas as carreiras escravistas); b) o impacto do tráfico de escravos na África, incluindo aqui o papel dos africanos e dos europeus como "agentes" do tráfico; c) a relação entre capitalismo e escravidão, ou seja, entre a gênese da economia industrial britânica e o escravismo colonial. Por último, argumento que esses três temas estão conectados por uma tese mais ampla de Inikori sobre a economia atlântica moderna.

\footnotetext{
${ }^{1}$ A tese chamou-se English Trade to Guinea: a Study in the Impact of Foreign Trade on English Economy, 1750-1807 e foi defendida na University of Ibadan, em 1973.

2 Sobre os sentidos e abordagens da história do Atlântico, Cf. GAMES 2006. A autora, inclusive, considera os estudos sobre o tráfico transatlântico de escravos como o ponto de partida desse campo de pesquisas: "First and foremost, historians of the transatlantic slave trade have been especially insistent about putting an Atlantic perspective at the center of their work, starting with Philip D. Curtin's painstaking efforts to calculate the size of the trade, and continuing with the innovative and extensive research on the African diaspora. [...] No other field has been so aggressively engaged for so many decades in pursuing an Atlantic vision and in framing the field as a whole" (GAMES 2006, p. 743).

3 "Revisionismo", aqui, não deve ser entendido no seu sentido estrito, ou seja, de contestação das principais teses marxistas, o que passou a se dar desde a virada do séc. XIX, mas num sentido lato, isto é, de crítica a teses historiográficas consagradas, mesmo que, no presente caso, algumas das teses sejam oriundas do campo marxista ou marxizante da historiografia. Veja-se, por ex., LOVEJOY 1997. O revisionismo, nesse caso, contesta os argumentos que apontam para a fragmentação cultural e, portanto, a impossibilidade de correlacionar as culturas negras na América com grupos étnicos da África específicos.
} 


\section{O tráfico atlântico de escravos africanos: o primeiro embate}

Desde os seus primeiros artigos, Inikori aliou a pesquisa documental ao debate metodológico e teórico para se contrapor às teses revisionistas sobre o tráfico transatlântico de escravos, incluindo o lugar do comércio e produção escravistas na formação da economia ocidental moderna e seu impacto sobre as sociedades envolvidas. Percebe-se tal relação em suas críticas às conclusões de Philip Curtin e de outros pesquisadores, cujos argumentos outro autor denominou como "escola minimalista" (M'BOKOLO 2003, p. 323), ${ }^{4}$ sobre o volume de escravos africanos transportados pelo Atlântico.

O livro de Philipp Curtin, The Trans-Atlantic Slave Trade: a Census (1969), foi um marco nos estudos quantitativos do tráfico escravista no Atlântico. ${ }^{5}$ Insatisfeito com as estimativas amplamente divulgadas sobre o tráfico transatlântico, - que variavam entre 13 milhões e 25 milhões de escravos - Curtin sintetizou todos os cálculos efetuados e os dados até então publicados acerca do tráfico transatlântico e dos desembarques na América, corrigindo as estimativas e acrescentando outras próprias. Assim, reduziu pela metade a estimativa total, até então difundida, de escravos desembarcados nos portos do Atlântico, de 20 milhões para cerca de 9,5 milhões, admitindo que esse número poderia chegar, no máximo, a 11 milhões (CURTIN 1969, p. 268-269, Tabela 77).

Não é necessário retomar aqui todos os trabalhos que se seguiram a esse, a maioria dos quais revisou, aumentando, parte dos números de Curtin (ANSTEY 1975; ELTIS; RICHARDSON 1989; LOVEJOY 1982, p. 474-475). Interessam-nos as críticas que Inikori fez às conclusões do Census e o debate que se seguiu com o seu autor. Os autores discordam, principalmente, sobre os testemunhos contemporâneos da quantidade de escravos desembarcados em certo período numa determinada colônia. Curtin tendeu a rejeitar a representatividade desses números como média de períodos maiores. O argumento do autor é o de que os desembarques flutuavam muito para que um ano (ou mesmo alguns anos) pudesse ser tomado como média (CURTIN 1969, p. 147-149).

Inikori afirmou que Curtin tendia a exagerar as flutuações anuais do volume do tráfico e escolher sempre os dados e testemunhos que apontassem para volumes menores de escravos desembarcados. Assim, submeteu vários dos cálculos e estimativas de Curtin a revisões sistemáticas, sempre concluindo por uma elevação dos resultados de suas estimativas (INIKORI 1976c, p. 613614). Por sua vez, Curtin argumentou que as críticas de Inikori tinham cunho político, daí sua preferência pelos "grandes números", pois, segundo o autor, para Inikori "[...] lower numbers carried by the slave trade decrease European guilt while high numbers will increase it" (CURTIN 1976, p. 596). Inikori considerou ingênua a imputação de enviesamento político, concluindo que "[...] whether Curtin/Inikori has a political motive or not is immaterial to the issue in hand" (INIKORI 1976c, p. 610). ${ }^{6}$

\footnotetext{
" Como afirma M'Bokolo: "O Census continua a ser a certidão de nascimento 'científico' da escola minimalista", que ele considera uma vertente revisionista.

${ }^{5}$ Sobre a importância desta obra para os estudos ulteriores, Cf. GEMERY; HOGENDORN 1979, p. 3.

${ }^{6}$ Apesar da afirmação de isenção pelos pesquisadores dos aspectos quantitativos do tráfico, uma autora
} 
O caso do tráfico de escravos para o Brasil ilustra com clareza a posição de cada um dos autores. Curtin valeu-se, sobretudo, dos estudos de Frédéric Mauro, David Birmingham (sobre as exportações de Angola) e Maurício Goulart (particularmente, sobre as importações da Costa da Mina) para estabelecer os números de importação pelo Brasil. Os dados estimados por Maurício Goulart $(1950)^{7}$ já reduziram em muito as estimativas correntes até os anos 1940. Ainda assim, Curtin preferiu reduzi-las ainda mais; após fazer alguns reparos quanto à confiabilidade de algumas estimativas de Goulart, julgando-as sobre-estimadas, concluiu que o Brasil tinha importado 3.648 .800 ou pouco mais de $38 \%$ do total dos desembarques na América (CURTIN 1969, p. 112-9, 206-10, 268, Tabela 77). Inikori questionou o argumento de Curtin de que os cálculos de Goulart fossem menos confiáveis do que os relativos a outras carreiras do tráfico atlântico (CURTIN 1969, p. 89, 210). Assim, a estimativa de 3.648.000 escravos importados pelo Brasil entre 1451 e 1870 foi considerada por Inikori "a serious understimate" (INIKORI 1976a, p. 205).

Inikori continuou a insistir em que os números aceitos pelos "minimalistas" estavam abaixo do volume efetivo, sugerindo como limites entre 15 milhões e 20 milhões de indivíduos deportados pelo tráfico atlântico (INIKORI; ENGERMAN 1992, p. 5-6). Mesmo com a publicação dos dados e análises do Trans-Atlantic Slave Trade Database - TSTD (1999; 2010; ELTIS; BEHRENDT 2000; ELTIS; RICHARDSON 2008; ELTIS; LACHANCE 2007), ${ }^{8}$ estimando um teto aproximado de 12,5 milhões de escravos exportados da África via Atlântico (ELTIS; RICHARDSON 2010, p. 37,43), ${ }^{9}$ Inikori continuou cético, como transparece em seu comentário sobre os dados apresentados no mais recente livro de Herbert Klein sobre o tema (1999), no qual utiliza os dados do TSTD, quando afirma:

Other difficulties worth mentioning include the volume of slave exports. Here figures are paraded with unwarranted certainty without telling the reader the quality of evidence upon which they are based. And when the authority of "most scholars" is invoked it is not clear whether the "most" refers to just a group of friends or it includes all scholars from Africa, the Caribbean, and the rest of the World (INIKORI 2002, p. 134).

Não por acaso, em seu livro mais recente (2005), Inikori simplesmente não menciona ou cita o The Trans-Atlantic Slave Trade, embora o volume do tráfico inglês, assim como o total atlântico, seja abordado na obra (Cf. MORGAN 2003, p. 875). A omissão explica-se pelas severas reservas que o autor manifestou sobre os resultados gerais delineados por D. Eltis e D. Richardson (2008). Embora Inikori tenha elogiado as contribuições específicas no volume que aqueles autores editaram, continuou a discordar da quantificação do

afirma, num balanço dos debates: "Correct calculation of the number of Africans taken from Africa and transported across the Atlantic continues to generate debate among scholars, contention having arisen on account of the difficulty of separating issues relating to the moral and emotional aspects of the transatlantic trade from its quantitative dimensions" (BECKLES 2000, p. 92).

7 Um senso do tráfico para o Brasil, similar ao de Curtin.

8 Disponível em http://slavevoyages.org/downloads/2010estimates-method.pdf. Acessado em 1/6/2012.

9 O total informado na base de dados on-line é 12.521.336: http://slavevoyages.org/tast/assessment/ estimates.faces. Acessado em 22/9/2012. 
volume total do tráfico: "Much of this otherwise excellent work of historical scholarship, however, is tainted by the unfathomable attempt by the editors, Eltis and Richardson, to mislead the reader on the issue of the overall number of captives shipped from Africa and landed in the Americas" (INIKORI 2011, p. 250). A principal queixa do autor refere-se ao fato de que os novos números totais apontados pelos organizadores do Trans-Atlantic Slave Trade Database são superiores aos apresentados em 1999 em mais de 13\% e, assim, muito próximos dos que Inikori havia proposto, o que o fez concluir: "Need it be said the weaknesses noted here are damaging to the credibility of the estimates of the overall size of the Atlantic slave trade presented in this volume by Eltis and Richardson" (INIKORI 2011, p. 251). Mesmo com a elevação significativa da estimativa total pelos organizadores do TSTD (bem superior, inclusive, à de Curtin), ela fica abaixo do total apontado por Inikori e Stanley Engerman: de 15 a 20 milhões de africanos traficados pelo Atlântico (INIKORI; ENGERMAN 1992, p. $5-6) \cdot{ }^{10}$

O "numbers game", ou seja, o debate sobre o volume do tráfico de escravos não teria sentido algum se ele se cingisse ao aspecto quantitativo per si (M’BOKOLO 2003, p. 325). No entanto, a insistência de Inikori em que Curtin subestimou o volume total do tráfico de escravos prende-se a considerações mais amplas. Dentre elas, uma de não menor importância entre os pesquisadores do tráfico e da economia atlântica na modernidade referese ao nível de lucratividade do tráfico britânico de escravos. A estimativa do volume maior ou menor de escravos transportados pelos ingleses influi diretamente no cálculo do nível de lucratividade do tráfico inglês (DARITY 1985, p. 697-8). Aqui, estamos às voltas, mais uma vez, com uma posição revisionista e sua contestação, pois a tese dos "superlucros" foi difundida por Eric Williams e passou a ser contestada nos anos 1960 em diante.

Inikori abordou os dois temas de forma relacionada em outros artigos. Num primeiro, colocou em questão os pressupostos de dois outros autores acerca da natureza do tráfico escravista britânico. ${ }^{11}$ Ao mesmo tempo, afirmou que os cálculos da lucratividade do tráfico escravista inglês realizados por Roger Anstey (1975, p. 46-50) estavam equivocados por subestimarem o número de escravos transportados pelos britânicos num determinado período do séc. XVIII, embora considerasse que a preocupação com os lucros em relação ao impacto do comércio atlântico sobre a economia pré-industrial britânica não fosse a mais relevante, dado que "[t]he contribution of the slave trade and slavery to the expansion of world trade between the fifteenth and nineteenth centuries constituted a more important role than that of profits" (INIKORI 1981, p. 746).

No entanto, o autor contestou fortemente as conclusões de Thomas e Bean baseadas na concepção dos autores de que o tráfico escravista britânico constituía uma estrutura de mercado competitiva e que, portanto, não dava lugar a lucros "anormais" (THOMAS; BEAN 1974, p. 886). Que Thomas e Bean

${ }_{10}$ Os autores consideram serem estes os limites mínimos e máximos.

${ }^{11} \mathrm{O}$ artigo em questão é THOMAS; BEAN 1974. 
tinham como um de seus objetivos (se não o principal) contestar a tese dos superlucros e sua contribuição ao desenvolvimento industrial britânico fica claro nos primeiros parágrafos do seu artigo:

Historians of slavery and the slave trade have often left us with the impression that the slave trade was fantastically profitable. The view that it was the profits from the slave trade which financed the British Industrial Revolution and the first industrialization of the United States appears to be gaining adherents (THOMAS; BEAN 1974, p. 885).

Inikori procurou demonstrar que os autores estavam enganados quanto ao seu principal pressuposto (a estrutura de mercado do tráfico atlântico de escravos), bem como em relação a outros pontos correlatos, ${ }^{12}$ apontando evidências do caráter monopolístico do tráfico inglês de escravos e a tendência a lucros altos no desempenho das grandes firmas dos portos escravistas, concluindo, enfim, que "[t]he profits were no normal profits of an easy trade" (INIKORI 1981, p. 776).

A resposta ao autor veio num artigo de B. L. Anderson e David Richardson (1983), no qual, como vimos também no tema acima, os autores contestam a metodologia, a interpretação das fontes e os pressupostos utilizados por Inikori, ou que atribuem a ele (ANDERSON; RICHARDSON 1983, p. 714-715). Os autores afirmam que a revisão para mais dos lucros do tráfico feita por Inikori é uma "reminiscência" das sugestões de Eric Williams, mas que as conclusões do autor se baseiam num número muito limitado de evidências para serem validamente generalizadas. Quanto à estrutura do mercado escravista transatlântico, concluem que "[t]he evidence points to a fiercely competitive environment in the British slave trade" entre os mercadores es portos, (ANDERSON; RICHARDSON 1983, p. 716-720).

Inikori respondeu às críticas dos autores, reafirmando, como era de se esperar, suas conclusões anteriores. Note-se, porém, que aqui fica mais claro que a questão da lucratividade e, sobretudo, da estrutura do mercado escravista são elementos no argumento mais amplo sobre o papel do tráfico escravista inglês na Revolução Industrial. Um dos argumentos do autor para os lucros anormais das grandes firmas refere-se à inelasticidade da oferta de bens para o tráfico (têxteis e armas, principalmente), que gerava vantagens para os grandes traficantes, que, com maior liquidez, obtinham mais facilmente os produtos necessários. Da constatação da oferta inelástica de manufaturados, em particular nos momentos de alta demanda, segue-se que "[i]n general, it was the supply bottlenecks that manufacturing under handicraft technology ran against during such periods in the eighteenth century that created the environment for the inventions and compelled their adoption in the industries" (INIKORI 1983, p. 726). Portanto, mais relevante que a questão dos lucros do tráfico é o ambiente econômico favorável ao desenvolvimento industrial que a expansão mercantil ligada ao escravismo atlântico propiciou. 
Quanto à questão do volume do tráfico, a polêmica continua, havendo apoiadores dos "minimalistas" e dos antirrevisionistas. Não obstante, apesar do debate, não houve uma só revisão das conclusões, parciais ou totais, da obra de Curtin, que não apontasse números superiores aos que ele calculou. Portanto, ainda que Curtin alegue que as suas estimativas foram computadas para serem revisadas, indicando uma expectativa de variação de $20 \%$ (para mais e para menos), Inikori alega que ele supunha que essas divergências se dariam nos casos das carreiras individuais, mas não no total estimado para todo o tráfico atlântico de escravos (INIKORI 1994, p. 46-47).

Já no caso da lucratividade, o debate parece ter se aproximado de um consenso. Kenneth Morgan considera que Richardson e Behrendt estão corretos em vista do tipo e da quantidade de fontes sobre as quais Inikori baseou o seu argumento. Por sua vez, William Darity Jr. considera que o debate sobre o caráter monopolístico ou não do tráfico escravista é uma falsa questão, pois "[t]he actual profitability of the slave trade cannot be determined by examining the industry's structure", ou seja, se era ou não monopolista (DARITY JR. 1985, p. 694). Este último autor também questiona as conclusões de outros pesquisadores quanto à relação entre os capitais provenientes dos lucros do tráfico escravista e o desenvolvimento industrial inglês. ${ }^{13}$ Não bastariam tais conclusões para lançar por terra os argumentos de Eric Williams, uma vez que "William's theory is more complex than the argument that profits from the slave trade were important source of funds for individual investment [na 182 indústria britânica]" (DARITY JR. 1985, p. 702), ponto sobre o qual Inikori me parece estar de pleno acordo. Em suma, a discordância entre Inikori, de um lado, e Anderson e Richardson (e Thomas e Bean), de outro, é tanto de método quanto de análise, pois, ao fim, reflete a aceitação e a rejeição, de cada parte, respectivamente, das teses de Eric Williams.

\section{O impacto do tráfico de escravos nas sociedades da África}

Num trabalho bastante influente, Walter Rodney (1982) procurou demonstrar o papel da Europa nas origens do subdesenvolvimento contemporâneo do continente africano. Um dos elementos ressaltados por Rodney concerne ao caráter deletério do tráfico de escravos sobre a economia das sociedades africanas atingidas pela escravização e o comércio de pessoas. Assim, ao argumento de que a África obteve "riquezas" em troca dos indivíduos que deportava, o autor responde: "This suggestion fails in take into account the fact that several European imports were competing with and strangling African products" (RODNEY 1982, p. 101). O setor mais importante a ser negativamente afetado foi o da produção têxtil, de forma que, diz Rodney, de produtoras e exportadoras de têxteis, as regiões envolvidas no tráfico com os europeus tornaram-se dependentes de importação: "[...] by the time that Africa entered the colonial era, it was concentrating almost entirely on the export of raw cotton and the import of manufactured cloth" (RODNEY 1982, p. 103-104).

${ }^{13}$ Ainda que eles estejam corretos quanto à baixa ou "normal" lucratividade do tráfico escravista. 
Essa tese seria contestada por alguns autores, que buscaram demonstrar que o comércio que envolvia a venda de escravos africanos para os europeus não afetara significativamente a economia africana e, portanto, não pode ser responsabilizada pelo seu subdesenvolvimento posterior. Pelo contrário, alguns pesquisadores argumentam que ao menos parte das sociedades envolvidas no comércio de pessoas escravizadas colheu benefícios do tráfico.

A controvérsia teve início com as críticas feitas por John Fage aos argumentos de Rodney acima citados. É significativo o ponto de partida dos argumentos daquele autor em relação aos avançados por este (e por outros): segundo Fage, as conclusões revisionistas ${ }^{14}$ foram criticadas devido ao fato de que o tema "must be highly emotive" (FAGE 1989, p. 97); ainda, especificamente em relação às teses de Rodney (no que concerne ao impacto socioeconômico do tráfico sobre a África), o autor as considera equivocadas, "perhaps by his ideological alignment" (FAGE 1989, p. 125). Portanto, de saída, os adversários das teses que atribuem importância fundamental ao tráfico escravista no ulterior evolver das sociedades africanas têm seus argumentos vinculados a reações emotivas e ideológicas. Veremos, à frente, a resposta de Inikori a essa posição.

Vejamos quais os argumentos de Fage: ele contesta que o comércio euroafricano tenha prejudicado as sociedades africanas, primeiramente porque "[t] here is a plenty of evidence to show that bargaining whites and blacks was conducted more or less on equal terms" (FAGE 1989, p. 103); segundo, porque um comércio desvantajoso e com consequências negativas para as sociedades africanas não teria se prolongado entre as duas partes. Como explica o autor:

In view of the considerable commercial experience available in West Africa by about the fifteenth century, it seems unlikely that African rulers and merchants would have provided slaves for sale to Europeans, and on the scale that they did, if they have thought that this would lead to demographic catastrophe, to a dramatic reduction in number of a ruler's subjects and of a society's productive workers. It must rather be supposed that they must commonly have had some underlying idea that it was more rewarding to exchange a proportion of the available labour force for the goods brought to them by the Europeans than it was to retain this labor and to use it to manufacture equivalent goods at home in Africa (FAGE 1989, p. 106).

Mesmo a importação de armas, que se relacionou ao aumento da violência na geração de escravos, é vista de forma positiva: "It is probably fair to say that in the circumstances of the slave trade, firearms could serve as a sort of economic multiplier. A society which used labour to purchase firearms could acquire the means to secure more labour than it had lost in the purchase" (FAGE 1989 , p. 107).

Os efeitos do comércio escravista atlântico sobre a África não poderiam ser tão negativos quanto Rodney argumentou, ainda segundo Fage, pois, esse ramo mercantil era, por um lado, um elo secundário no conjunto do sistema 
de trocas "intra-africano" e, por outro, fornecia aos africanos bens que eles, ou não poderiam produzir, ou o fariam com custos mais altos (FAGE 1989, p. 115). Enfim, mesmo tendo exportado, pelo menos, onze milhões de pessoas, não foram os mais hábeis nem os mais produtivos que os europeus carrearam para fora da África, mas "[...] it was more likely that it would be rejects from the African system, the less productive or more recalcitrant slaves [...]" (FAGE 1989, p. 115).

Os argumentos revisionistas foram ainda mais elaborados. Contestando o que qualificou de "posição pessimista" sobre os efeitos do comércio euro-atlântico relacionado ao tráfico escravista sobre as economias da África, John Thornton (2004, p. 48-88) apresenta elementos que se propõem a invalidar aquela abordagem. Segundo o autor, o fato de que os bens importados pela África em troca dos escravos eram não essenciais, que eram apenas suplementares à oferta doméstica e constituíam uma cesta de bens de consumo suntuário, permite-Ihe concluir que

[...] o comércio da Europa com a África não pode ser visto como algo destrutivo, pois ele não espoliou nenhuma linha de produção africana nem impediu o desenvolvimento fornecendo produtos que poderiam ser manufaturados na África, mesmo quando se faz a diferença entre tecidos ou aço de boa ou má qualidade (THORNTON 2004, p. 99).

Nesse mesmo sentido concluíram David Eltis e Lawrence Jennings após a exposição e análise de dados quantitativos sobre as importações africanas de manufaturas: "[...] despite the rapid growth of Atlantic trade and the steady shift in the terms of trade in Africa's favor, the rough quantitative evidence suggests that European products were only beginning to make an impact on Africa by the 1860s" (ELTIS; JENNINGS 1988, p. 957).

Inikori contestou a maior parte de tais argumentos, a começar pela pecha de que os argumentos antirrevisionistas são ideológicos. O autor assinala o caráter particularmente controverso da historiografia do tráfico atlântico de escravos, em parte pelo receio das sociedades envolvidas de verem-se, atualmente, como responsáveis ou beneficiárias do tráfico, resultando disso que "it is extraordinarily easy for some participants in the debate to invoke ideology. Hence, charges of ideology are sometimes substituted for serious scholarly investigation" (INIKORI 1994, p. 37).

No entanto, afirma Inikori, o que normalmente se verifica é uma má compreensão, por parte dos revisionistas, dos pressupostos teóricos que embasam os argumentos daqueles que afirmam que o tráfico atlântico de escravos está nas origens do subdesenvolvimento africano. ${ }^{15}$ Dessa forma, ele começa por esclarecer os conceitos fundamentais hauridos da teoria da dependência e do subdesenvolvimento e que subjazem à análise do desenvolvimento africano no longo prazo. ${ }^{16}$ Nesse sentido, argumenta ainda, as conclusões tiradas pelos

\footnotetext{
${ }^{15}$ Não obstante, ele considera que Walter Rodney foi o primeiro a alegar que os revisionistas padeciam de um viés ideológico.

${ }_{16}$ Inikori atribui a Paul Baran e Ander Gunder Frank as origens da teoria da dependência e a análise do subdesenvolvimento; ele assinala que a ênfase sobre os efeitos unilaterais de influências externas sobre as sociedades "dependentes" foi modificada, como reação a críticas "construtivas e destrutivas", levando
} 
revisionistas pecam justamente por aplicarem ao objeto em questão (os efeitos do tráfico atlântico sobre a economia africana) um arsenal teórico inadequado (INIKORI 1994, p. 37-44).

É o caso dos argumentos que apontam para os ganhos dos grupos africanos diretamente envolvidos na venda de escravos, como os de Fage na passagem citada anteriormente. Inikori contesta-os, apontando que os equívocos da análise se devem ao que chama de "tirania do paradigma" (no caso, a abordagem neoclássica): "Fage's paradigm did not allow him to distinguish between the selfinterest of ruling classes and social interest; [...]; between the collective interests of stronger communities and those of weaker ones" (INIKORI 1994, p. 48). Ou seja, o argumento revisionista confundiria ganhos privados com os benefícios coletivos, quando aqueles se deram em detrimento dos últimos. Mais ainda, Fage e, da mesma forma, Thornton não distinguem os ganhos de curto prazo dos efeitos de longo prazo. Ao enfatizarem a participação voluntária de lideranças políticas africanas no tráfico escravista com os europeus, julgam os autores que invalidam os argumentos de que tal mercancia fosse prejudicial à África, ao que responde Inikori: "Thornton is conceptually misled into believing that those who argue for a serious negative impact of the trade on Africa economies and societies must be arguing at the same time that individual African participants were forced against their will by the European traders". Tais autores não negam tal participação, nem que ela tenha gerado ganhos privados; porém: "long term development of socially efficient institutional arrangements and production relations was sacrificed for the short-term private benefit of a few individuals and ruling classes" (INIKORI 1994, p. 53).

O autor questiona, igualmente, os argumentos sobre o papel do tráfico de escravos para a economia africana. ${ }^{17}$ As questões colocadas por Eltis e Jennings, de acordo com ele, são inadequadas, mais uma vez por derivarem do paradigma neoclássico. Quando concluem, baseados em estimativas de valores de renda per capita em relação aos valores do comércio externo, que o valor dos bens recebidos em troca dos escravos correspondia a uma fração irrelevante do mercado doméstico de certas regiões africanas, Inikori considera que se trata de uma medida enganosa, dado que, provavelmente, mais de $95 \%$ do produto interno bruto da África Ocidental era composto por bens e serviços não comercializados. Portanto, "[t]he role of the Atlantic slave trade in the dynamic process of socioeconomic change can be accurately gauged only when it is related to the size of the market sector of the region's domestic economy at the time" (INIKORI 1994, p. 51). Um argumento semelhante é apresentado por Paul Lovejoy, que aponta para o impacto desproporcional do comércio escravista sobre as sociedades africanas. Ele também considera que a "ratio of the value of

à ênfase na evolução da estrutura de classes interna como resposta a influências externas prolongadas (INIKORI 1994, p. 38-39). Curiosamente, no entanto, o autor omite completamente a contribuição de F. H. Cardoso e E. Faletto para essa versão da teoria da dependência, cujos argumentos tiveram forte influência fora do Brasil, inclusive nos EUA (Cf. MANTEGA 1997, p. 38-50).

$17 \mathrm{O}$ autor também contraria os argumentos de John Fage e Joseph Miller quanto ao impacto demográfico, mas iremos nos concentrar nas questões econômicas. Outros autores também afirmam o impacto demográfico negativo do tráfico de escravos sobre as sociedades africanas envolvidas, como MANNING; LOVEJOY 1989, p. 387-388. 
the external trade to per capita income is not an accurate indicator of the impact of the slave trade in Africa", pois, dado o caráter das economias locais, "[a]lmost any incremental increase over subsistence would have had a disproportionate impact on the economy" (LOVEJOY 1989, p. 387).

Uma vez que na Europa da Idade Moderna, especialmente na Inglaterra, desenvolvia-se uma protoindústria cujo principal produto eram os têxteis e que eles (tecidos de algodão oriundos da Índia e da Europa) constituíam o principal bem comercializado em troca dos escravos no litoral da África atlântica, Inikori procura demonstrar que a exportação de cativos em troca das manufaturas europeias e asiáticas se constituiu num sério obstáculo ao desenvolvimento do setor têxtil na África ocidental. ${ }^{18}$ A demonstração dessa tese dá-se de forma indireta, uma vez que há poucos dados quantitativos concernentes à economia interna da África no período. Primeiro, pela análise do grau de protoindustrialização atingido pelo setor de manufaturas:

This level of industrial development is characterized, in the main, by the transformation of previously independent, small-scale producers of manufactures into semi-wage workers by Merchant capitalists who take over the supply of raw materials (and also tools in many instances), the organization of production, and the marketing of the final product in distant markets (including overseas markets) (INIKORI 2009, p. 88).

O autor ressalta, porém, que o escopo da análise deve ir além dessa relação tráfico de escravos/manufaturas africanas: "It must probe into in addition the impact on overall growth of production, local and interregional specialization, and the development of domestic markets for manufactured and other goods" (INIKORI 2009, p. 88). Em seguida, analisa os dados de importação de bens em troca da exportação de escravos, que revelam as tendências das transformações da economia interna da África Ocidental.

A análise combinada dessas informações conta a seguinte história, de acordo com Inikori: até o séc. $\mathrm{XV}$, desenvolveu-se um comércio dentro das regiões da África Ocidental (entre o litoral e o interior das regiões que viriam a ser conhecidas pelos europeus por Costa do Ouro e Golfo de Benin), o qual levou a uma divisão inter-regional da produção, com áreas produzindo têxteis (e outras manufaturas artesanais) em troca de alimentos, noz de cola e ouro. Quando os comerciantes europeus chegaram ao litoral atlântico, eles se tornaram intermediários no comércio de cabotagem que ligava a Baía de Benin à Costa do Ouro, já modificando as relações entre as sociedades africanas. ${ }^{19}$ Todavia, nos dois primeiros séculos das relações euro-africanas na África Ocidental, a intensificação das exportações, não apenas de escravos, mas também de manufaturas (os têxteis do Benin), levou ao estabelecimento de um quasi putting-out system (INIKORI 2009, p. 100) nas áreas produtoras de têxteis,

\footnotetext{
18 O autor faz questão de assinalar, porém, que dizer "that industrial development or general economic development was retarded by the import of manufactures in exchange for captives does not imply that West Africa would have achieved an industrial revolution during the period in absence of the Atlantic slave trade" (INIKORI 2009, p. 87).

19 Este argumento foi defendido originalmente por Walter Rodney (1982, p. 103-104, 110).
} 
indicativo de um efetivo desenvolvimento das forças produtivas; igualmente, propiciou a expansão da economia de mercado, condição necessária para o incremento das manufaturas acima do nível doméstico e artesanal (INIKORI 2009, p. 89-100).

No entanto, a partir do final do séc. XVII, all this changed (INIKORI 2009, p. 103). Até então, as áreas envolvidas no comércio com os europeus estavam importando, sobretudo, moedas ${ }^{20}$ (cauris, manilhas, varões de cobre) ou ferro como matéria-prima, o que indica que as importações supriam liquidez a um comércio interno em expansão e abasteciam os produtores de manufaturas. Com o rápido aumento da demanda da América por escravos, ${ }^{21}$ os europeus mudaram da demanda por manufaturas africanas para os escravos a serem vendidos no outro lado do Atlântico; assim, cresceu continuamente a oferta de têxteis da Índia e europeus em troca dos escravos, o que alterou completamente a pauta de importações da África Ocidental. Ao longo do séc. XVIII, a participação das "moedas" e das matérias-primas reduziu-se continuamente, enquanto crescia a dos têxteis e a de armas de fogo, chegando esses produtos a compor $3 / 4$ das importações cerca de 1790 (INIKORI 2009, p. 101-104, Tabelas 3.2 e 3.3).

O aumento da importação de armas de fogo também revela o impacto político-econômico do comércio escravista com os europeus. À medida que os governantes locais foram se tornando incapazes de atender à demanda europeia por escravos pelos meios tradicionais, a captura (por meio de guerras, razias, rapto) tornou-se uma fonte importante de cativos, disseminando o conflito político entre as unidades territoriais já bastante fragmentadas, as quais encontraram na utilização de armas de fogo um acréscimo do potencial militar e, consequentemente, de produção de escravos (INIKORI 1977, p. 351; 2009, p. 103). ${ }^{22}$ A fragmentação política das sociedades africanas, exacerbada pelo tráfico de escravos, pode ser considerada um elemento a mais para o estabelecimento de relações pouco equilibradas entre os europeus (oriundos de Estados territoriais mais amplos) e os africanos, a despeito do tão enfatizado caráter voluntário dessas relações (BAILEY 2005, p. 62). ${ }^{23}$ Por fim, se a maioria dos têxteis ofertados aos governantes e mercadores africanos em troca de escravos era de origem indiana até fins do séc. XVIII, isso mudou daí em diante, com as transformações operadas na produção inglesa, que suplantou rapidamente os têxteis da Índia no mercado atlântico (INIKORI 2009, p. 106-111).

\section{Capitalismo e escravidão: a retomada de Eric Williams}

O trabalho de maior dimensão de Inikori é, até certo ponto, uma síntese do que ele vinha apresentando e debatendo desde os anos 1970, mas com um foco mais preciso. Pode-se remontar a um capítulo que escreveu para uma

\footnotetext{
20 O mais correto, talvez, seja falar de "mercadorias-moeda", de acordo com o termo cunhado por BRAUDEL 1970, p. 365-366.

${ }^{21}$ Isto deve ser atribuído à demanda combinada do Brasil, das Antilhas e das colônias fumageiras da América inglesa.

22 Em Inikori (1977) encontram-se amplos dados quantitativos sobre a importação de armas pela África Ocidental na segunda metade do séc. XVIII.

${ }^{23}$ Tal ênfase também tornou-se moeda corrente em parte da historiografia brasileira; Cf. FERREIRA 2010, p. 489 et seq., onde se fala da "supremacia africana" no comércio escravista em solo africano.
} 
publicação promovida pela UNESCO sobre o tráfico transatlântico de escravos em 1978. ${ }^{24}$ Nele, já vários dos argumentos que o autor sustentou em outros escritos posteriores estão formulados sinteticamente, ${ }^{25}$ como a distinção conceitual entre crescimento e desenvolvimento econômico, que considera fundamental para aquilatar o impacto do tráfico atlântico de escravizados na sociedade e economia africanas. ${ }^{26}$

Após um quarto de século debatendo sobre a história atlântica, o autor voltou à clássica tese de Eric Williams acerca da contribuição do tráfico atlântico escravista (de pessoas e bens) para o desenvolvimento econômico da Inglaterra em Africans and the Industrial Revolution in England (2002). O próprio autor constata que os argumentos históricos que apontam para a importância do comércio exterior nas origens da Revolução Industrial inglesa ${ }^{27}$ foram alvo de duras críticas e estiveram em baixa durante as décadas de 1970 e 1980, depois de terem predominado nas duas décadas anteriores, o que Inikori atribui à conjuntura crítica na economia mundial do período, em que o comércio exterior não pareceu relevante para o dinamismo das economias internacionais (INIKORI 2002, p. 91-140).

Na obra clássica de Williams (1975) destacam-se duas teses: a de que o comércio atlântico, em particular o tráfico de escravos, deu uma contribuição incontestável ao desenvolvimento industrial da Inglaterra; e a de que, quando a importância econômica das Antilhas inglesas declinou, depois da independência das colônias inglesas continentais, as elites econômicas e o 188 governo da Grã-Bretanha voltaram-se contra o tráfico escravista. As principais críticas à primeira dessas teses consistem na contestação de que o tráfico escravista fosse anormalmente lucrativo e de que os lucros oriundos do tráfico tivessem contribuído significativamente para a economia inglesa (Cf. ANSTEY 1975).

Como indicou Inikori, após os severos ataques às teses de Williams, esses argumentos revisionistas foram, por sua vez, contestados por outros autores. Sobre a relação entre os lucros do comércio colonial - incluindo o tráfico de escravos - e a economia inglesa, alguns autores consideraram sua contribuição como pouco expressiva devido a que o volume dos recursos gerados pelo tráfico era pequeno quando comparado ao produto nacional britânico (O'BRIEN 1982)..$^{28}$ Outros autores criticaram tal raciocínio, que passou a ser chamado de "argumento das pequenas proporções", arguindo que a comparação válida não devia ser entre o produto nacional e os lucros (ou recursos) do tráfico, mas entre

\footnotetext{
${ }^{24}$ De fato, tratava-se de comunicações apresentadas numa reunião no Haiti: "La traite négrière du $\mathrm{xv}$ au xix siècle: documents de travail et compte rendu de la réunion d'experts organisée par l'Unesco à Port-au-Prince, Haïti, 31 janvier - 4 fevrier 1978" e, posteriormente, publicadas.

25 Por se tratar, provavelmente, de síntese de sua tese de doutorado: INIKORI 1973.

${ }^{26}$ Cito pela tradução portuguesa; até onde sei, este é o único trabalho de Inikori traduzido para o português. O autor aborda, ainda, sem aprofundá-la, a questão do desenvolvimento desigual das economias atlânticas. Nesse ponto, o elemento central de seu argumento é o papel da divisão internacional do trabalho, que, na forma apresentada, constitui-se numa divisão atlântica do trabalho na qual as sociedades da Europa Ocidental e, em parte, a Nova Inglaterra exerceram o comércio, transporte, finanças e produção de manufaturas, enquanto o restante da América colonial (em particular a América Latina e o Caribe) concentrou-se na produção de bens primários (metais preciosos e bens agrícolas). A África, por sua vez, não teve uma função produtiva, limitando-se à "compra e venda de mão-de-obra servil" (INIKORI 1979, p. 74-75; citação nesta última).

${ }^{27}$ Que é o foco central do livro, cujo subtítulo é A study in international trade and economic development.

$28 \mathrm{Um}$ dos primeiros a argumentar nesta linha foi Roger Anstey (1975, p. 22-24).
} 
eles e o montante investido no setor manufatureiro, ao qual, sabidamente, o tráfico escravista estava ligado (SOLOW 1987; DARITY JR. 1994, p. 250-256). ${ }^{29}$

Das ideias fundamentais de Williams, Inikori reafirmou a que considera o tráfico de escravos e a economia escravista atlântica fatores fundamentais para o advento da Revolução Industrial na Inglaterra, ou, como ele resume, "the book focuses on the contribution of Africans to the successful completion of the industrialization process in England from the mid-Seventeenth to the mid-Nineteenth century" (INIKORI 2002, p. XVI). Tal contribuição, obviamente, não é apresentada de forma simples e direta; pelo contrário, ela enquadra a relação entre a economia escravista moderna e as transformações socioeconômicas na Inglaterra num escopo cronológico e espacial bem mais amplo. Numa outra passagem do texto citado, o argumento é claramente colocado:

The growth of England's international trade in $1650-1850$ is shown as a function of the growth of Atlantic commerce that linked together the main regions of the Atlantic basin. In turn, the growth of Atlantic commerce during the period is explained in terms of the employment of Africans as forced, specialized producers of commodities for Atlantic commerce at a time when the prevailing conditions encouraged small-scale subsistence production by legally free producers (INIKORI 2002, p. XVII).

O autor retoma, portanto, o argumento de que uma revolução comercial - alicerçada na escravidão mercantil moderna - precedeu e impulsionou a revolução fabril (DAVIS 1967; INIKORI 2000, p. 51). Nesse sentido, Inikori analisa as transformações econômicas na Inglaterra na perspectiva de longuíssima duração, indo bem além do recorte cronológico adotado por outros autores anteriormente, ${ }^{30}$ pois aborda o tema desde o séc. XI, lançando mão de estudos sobre a economia inglesa medieval e moderna. O intento é demonstrar que as modificações na estrutura agrária ao longo de oito séculos (a "revolução agrícola" que se "acelera", particularmente, a partir do séc. XVI) não é o fator preponderante por trás da Revolução Industrial, pois não foram as regiões ou condados mais avançados no processo de enclosure e mercantilização do campo os que experimentaram as transformações manufatureiras que desembocaram na revolução industrial. As regiões que o fizeram, indica, foram as diretamente ligadas à ascensão do comércio atlântico (ligado, também, à rota do Índico) nos séculos XVII e XVIII, ou seja, o West Riding e o Lancanshire (INIKORI 2002, p. 72-81, 475-476).

Ele já havia sustentado a tese de que o comércio atlântico teria atuado como um multiplicador, estimulando diversos setores de serviços e produtivos na Inglaterra (INIKORI 1979, p. 78-83); porém, na versão mais recente, o viés dependentista, claramente presente naquele trabalho, praticamente desapareceu, dando lugar a uma abordagem baseada em teorias desenvolvimentistas,

\footnotetext{
${ }^{29}$ De forma análoga, Javier Cuenca Esteban demonstrou a importância das exportações para o crescimento marginal da indústria têxtil britânica na última década do séc. XVIII e primeira metade do séc. XIX (CUENCA ESTEBAN, 1997).

30 Veja-se, como um dos melhores exemplos da abordagem que enfatiza o papel da revolução agrícola inglesa nos séculos XVII e XVIII, DEANE; COLE 1962. Para uma abordagem marxista que também enfatiza as transformações agrárias, Cf. WOOD 2000.
} 
fundamentando-se, inclusive, em Adam Smith, particularmente em sua definição do comércio exterior como uma vent for surplus, responsável pelo aprofundamento da divisão social do trabalho (INIKORI 2002, p. 126-129; SMITH 2003, p. 7-28).

$\mathrm{O}$ aspecto mais renovador da abordagem adotada pelo autor consiste na interpretação da Revolução Industrial inglesa como o primeiro processo bemsucedido de industrialização por substituição de importações e de re-exportações (INIKORI 2002, p. 10). Primeiro, ele demonstra que havia uma demanda interna inglesa pelos têxteis de algodão asiáticos, a qual, após a proibição de sua importação no início do século XVIII, passou a ser suprida pela indústria têxtil inglesa emergente. No entanto, por si só, essa substituição de importações não seria suficiente para levar à "decolagem" do processo industrial. Foi necessário que a indústria inglesa competisse no Atlântico (em particular na África Ocidental) com produtores de outras nacionalidades para suprir o tráfico de escravos, substituindo, paulatinamente, a oferta asiática e da Europa continental de manufaturas (têxteis, armas e utensílios domésticos) (INIKORI 1979, p. 78-79; 2002, p. 10, 405-406 et seq.). ${ }^{31}$ Certamente que a abordagem teórica do autor suscitará debates entre os especialistas, como já salientou Pat Hudson:

More questionable is whether, as Inikori argues, England was the first successful case of import substitution industrialization (ISI) and reexport substitution industrialization (RSI). ISI and RSI theories have been developed to explain differential patterns of industrial growth in the twentieth century. Applying these to England two centuries earlier runs the risk of neglecting major differences in the context of international relations, in capital supply, and in technologies of production (HUDSON 2004, p. 434).

Para embasar a relação do tráfico atlântico e da produção escravista na América com o desenvolvimento de setores chave da economia inglesa (navegação, finanças, manufaturas) no século XVIII, o autor fundamenta-se em extensas pesquisas de arquivo. ${ }^{32}$ Esse conjunto de dados confere bastante força aos argumentos do autor, uma vez que qualquer contestação de suas teses terá de apontar erros metodológicos e/ou de interpretação, ou, então, elaborar novos dados. Parece-me impossível simplesmente ignorá-los, ainda que, talvez, esse seja um flanco vulnerável do livro, como observou um comentador, afirmando que a ênfase no caráter quantitativo dos argumentos do livro "makes Inikori less critical of his data and their provenance than he should be. Some of his attempts to quantify at each step of his argument are

\footnotetext{
31 Apesar de mencionar a importância do desenvolvimento interno do Ocidente europeu até o séc. XVI, favorável ao estabelecimento de um mercado mais amplo, o autor afirma a proeminência do comércio atlântico para o ulterior desenvolvimento industrial da Grã-Bretanha, com o mesmo argumento acima mencionado: "No início, foi na costa ocidental da África que a indústria algodoeira inglesa teve que enfrentar a concorrência muito cerrada dos tecidos de algodão de todas as regiões do mundo, em particular dos [têxteis de algodão da Índia]. A reação desta indústria perante uma tal concorrência contribuiu bastante para a tornar competitiva a partir do fim do século XVIII" (INIKORI 1979, p. 79).

32 Os dados destas pesquisas são apresentados ao longo de seis capítulos, em 40 tabelas, além de num apêndice estatístico.
} 
questionable, as with the estimate of investment in shipping where choice of multiplier is crucial" (HUDSON 2004, p. 435).

Não obstante, a importância do trabalho tem sido afirmada por alguns historiadores que não o consideram questionável a priori apenas por remeter às teses de Eric Williams:

In evaluating the role of Africans in the widest sense, Inikori transcends the earlier contested argument of Eric Williams while rehabilitating its intentions and providing a detailed set of new propositions. These will engage and provoke a wide range of historians for some time to come, particularly at a time when supply-side theories of the causes of the Industrial Revolution are on the wane (HUDSON 2004, p. 435).

A contribuição fundamental de Joseph E. Inikori consiste, enfim, em trazer de volta um debate, não apenas historiográfico, mas de imensa atualidade e de interesse amplo, que muitos consideravam superado, ${ }^{33}$ combinando com maestria uma abordagem teórica renovada com densas pesquisas de arquivo.

\section{Considerações finais}

A década de 1990 testemunhou uma crise das "metanarrativas" e, com elas, houve uma ampla desconfiança (nas Ciências Sociais, mas para além delas) em relação ao marxismo e a qualquer teoria estrutural (PALMER 1999, p. 75 et seq.), o que, finalmente, promoveu um relativo abandono das análises de longa duração, tão caras à história econômica até então. Análises que privilegiassem a relação entre centro e periferia e vinculassem o subdesenvolvimento (palavra, ainda hoje, fora de moda) de boa parte das economias do mundo à emergência de algumas economias ricas no Ocidente passaram por obsoletas (SCHWARZ 1999, p. 86; BEINSTEIN 2009, p. 42-43).

Não obstante essas transformações nas ciências sociais, que relegaram a um segundo plano temas clássicos da historiografia (no Brasil e alhures), alguns autores não deixaram de manter os seus interesses e pesquisas vinculados à história econômica (que cedeu amplo espaço à história cultural) e de privilegiar uma abordagem de longa duração dos fenômenos históricos. Parece-me que a trajetória da historiografia de Joseph Inikori representa bem um desses casos, pois o autor continuou a contestar as teses revisionistas quando elas encontraram boa acolhida entre os pesquisadores. Mais ainda, o autor não se aferrou simplesmente a argumentos consagrados, mas ampliou e aprofundou as pesquisas documentais sobre temas clássicos da história econômica e adensou a abordagem teórico-metodológica dos objetos em questão.

Quando observamos que os embates entre Inikori e outros autores sobre o tráfico transatlântico de escravos (e sobre a história atlântica de forma geral) envolvem a metodologia e a interpretação das fontes, isso nos permite salientar que nenhuma opção metodológica é isenta de pressupostos teóricos. Portanto, não faz sentido contestar a interpretação de qualquer pesquisador 
simplesmente apontando seus pressupostos teóricos e atribuindo-lhe, por isso, um enviesamento. ${ }^{34}$ Formulou-o de forma exemplar Barbara Solow: "Every census is simultaneously a social construct and an empirical statement about the real world, objective and subjective at the same time. [...] [and] reflects the conceptual framework of its constructors" (SOLOW 2001, p. 10).

É preciso ressaltar, no entanto, que não se pode concluir por uma clivagem nítida entre os revisionistas e os antirrevisionistas em todos os temas abordados pelo autor. Um autor pode estar de acordo com os argumentos clássicos sobre uma certa questão, mas em discordância no que concerne a uma outra. Podese ilustrar esse ponto a partir da questão do volume do tráfico atlântico de escravos e o seu impacto sobre as sociedades africanas: quanto ao primeiro termo, Paul Lovejoy reafirmou a validade das estimativas gerais de Philip Curtin; porém, ele tem defendido que houve consequências deletérias do tráfico sobre as estruturas das sociedades africanas (LOVEJOY 1982, p. 499; LOVEJOY 1989). Portanto, ser revisionista num tema não implica sê-lo em outro correlato.

As teses e os contra-argumentos elaborados por Joseph Inikori se coadunam num conjunto que constitui uma tese ampla sobre a história do Atlântico na Idade Moderna, a saber, que o evolver das sociedades relacionadas pelo comércio transatlântico escravista nos três continentes foi interligado de forma que a prosperidade econômica crescente da Europa ocidental (a começar pela Grã-Bretanha) se deu às custas da estagnação (mesmo que relativa) no desenvolvimento de outras áreas do Atlântico, em particular da África.

192 Igualmente, o autor afirma que os africanos deram um aporte essencial àquele desenvolvimento pelos efeitos positivos do tráfico de escravizados e da produção escravista de exportação nas Américas para a economia britânica. Enfim, que:

[...] it is thus clear that western [sic] Europe and North America were gainers in the Atlantic slave trade. Tropical Africa was a loser. [...] On the whole, nevertheless, the greatest losers of all were, without question, the enslaved peoples of Africa and the Americas (INIKORI; ENGERMAN 1994, p. 17). ${ }^{35}$

Os temas analisados pelo autor nas últimas quatro décadas são de profunda importância para a compreensão do passado e do presente das sociedades ocidentais, tal como afirma um historiador: "Economic history faces no more important question, whether asked by economists or by historians, than why industrialization and the reduction of mass poverty first started, and especially why it continued" (MCCLOSKEY 2010, p. 23). Inikori tem tido o mérito de contribuir substancialmente para esse debate e insistir em contestar supostos consensos. A sua obra proporciona um contraponto à historiografia sobre a formação do Brasil que tem tomado como pressuposto a desvinculação e, ainda mais, a não subordinação da economia colonial ao sistema econômico atlântico,

\footnotetext{
${ }^{34}$ Isto pode parecer uma obviedade, mas, como indicado no artigo, não é incomum que autores que se filiam às interpretações clássicas da historiografia da economia moderna sejam criticados por seus pressupostos, sem que se entre no mérito da análise e dos dados apresentados.

${ }^{35}$ Apesar de creditada aos dois autores, fica claro, nesta introdução, que se trata de uma síntese dos diversos argumentos até então apresentados por Inikori.
} 
com suas hierarquias e injunções (FRAGOSO; FLORENTINO 2001; FRAGOSO 2002; FRAGOSO; GOUVEIA; BICALHO 2000). Tal vertente teria muito a ganhar, hoje em dia, se, não digo adotasse as teses clássicas e antirrevisionistas, mas se não as ignorasse e, muito menos, as desse por mortas e enterradas, sugerindo um consenso que está longe de existir.

\section{Referências bibliográficas}

ANDERSON, B. L.; RICHARDSON, David. Market Structure and Profits of the British African Trade in the Late Eighteenth Century: A Comment. The Journal of Economic History, Vol. 43, no 3, p. 713-721, set. 1983.

ANSTEY, Roger. The Atlantic Slave Trade and British Abolition, 1760-1840.

Londres: Cambridge University Press, 1975.

BEINSTEIN, Jorge. Capitalismo senil: a grande crise da economia global. Traduzido por Rita Vinagre. Rio de Janeiro: Record, 2001.

BITTENCOURT, Marcelo; FERREIRA, Roquinaldo. A trajetória de um intelectual africano: entrevista com Toyin Falola. Tempo, Rio de Janeiro, no 20, p. 177-186, 2012.

BRAUDEL, Fernand. Civilização material e capitalismo: séculos XV-XVIII. Lisboa: Cosmos, 1970.

CUENCA ESTEBAN, Javier. The Rising Share of British Industrial Exports in Industrial Output, 1700-1851. The Journal of Economic History, Vol. 57, no 4, p. 879-906, dec. 1997.

CURTIN, Philip D. The Atlantic Slave Trade: a Census. Madison, Wisconsin: University of Wisconsin, 1969.

DARITY JR., William. The Numbers Game and the Profitability of the British Trade in Slaves. The Journal of Economic History, Vol. 45, no 3, p. 693-703, sep. 1985.

. British Industry and the West Indies Plantations. In: ENGERMAN, Stanley

L. (ed.). The Atlantic slave trade: effects on economies, societies, and peoples in Africa, the Americas, and Europe. Durham: Duke University Press, 1998, p. 247-279.

DAVIS, Ralph. A Commercial Revolution: English overseas trade in the seventeenth and eighteenth centuries. London: Historical Association, 1967.

DEANE, Phyllis; COLE, W.A. British economic growth, 1688-1959. Cambridge: Cambridge University Press, 1962.

ELTIS, David; JENNINGS, Lawrence C. Trade between Western Africa and the Atlantic World in the Pre-Colonial Era. The American Historical Review, Vol. 93, no 4, p. 936-959, Out. 1988.

; RICHARDSON, David (org.). Extending the Frontiers: Essays on the New Transatlantic Slave Trade Database. New Haven, CT and London: Yale University Press, 2008. 
; BEHRENDT, S.; RICHARDSON, D. A participação dos países da Europa e das Américas no tráfico transatlântico de escravos: novas evidências. Afro-Ásia, 24, p. 27-29, 2000.

; LACHANCE, Paul F. Estimates of the Size and Direction of Transatlantic Slave Trade. Disponível em: http://www.slavevoyages. org/downloads/estimates-method.pdf Acesso em: 26 de julho de 2012.

FAGE, John D. African societies and the Atlantic slave trade. Past and Present, Vol. 125, 1, p. 97-115, 1989.

FERREIRA, Roquinaldo. A primeira partilha da África decadência e ressurgência do comércio português na Costa do Ouro (ca. 1637 - ca. 1700). Varia Historia, Belo Horizonte, Vol. 26, no 44, p. 479-498, jul/dez 2010.

FRAGOSO, J.; FLORENTINO, M. O Arcaísmo como Projeto: mercado atlântico, sociedade agrária e elite mercantil em uma economia colonial tardia Rio de Janeiro, c. 1790 - c. 1840. 4a ed. revista. Rio de Janeiro: Civilização Brasileira, 2001.

. Para que serve a história econômica? Notas sobre a história da exclusão social no Brasil. Estudos Históricos, Rio de Janeiro, no 29, p. 3-28, 2002.

; GOUVÊA, Maria de Fátima Silva; BICALHO, Maria Fernanda Baptista. Uma leitura do Brasil colonial: bases da materialidade e da governabilidade no Império. Penélope, no 23, p. 67-88, 2000.

194 GAMES, Alison. Atlantic History: Definitions, Challenges, and Opportunities. The American Historical Review, Vol. 111, no. 3, p. 741-757, jun. 2006.

GOULART, Maurício, A Escravidão Africana no Brasil: das origens à extinção do tráfico. São Paulo: Martins Fontes, 1950.

HUDSON, Pat. [Resenha de:] INIKORI, Joseph E. Africans and the Industrial Revolution in England: A Study in International Trade and Economic Development. The Journal of Modern History, Vol. 76, no 2, p. 434435, jun. 2004.

INIKORI, Joseph E. Measuring the Atlantic Slave Trade: An Assessment of Curtin and Anstey. The Journal of African History, Cambridge University Press, Vol. 17, no 2, p. 197-223, 1976a.

Slave Trade and the Atlantic Economy, 1451-1870. Working Paper. Paris: UNESCO, 1976b. Disponível em: http://unesdoc. unesco.org/images/0002/000213/021379Eb.pdf Acesso em: 12 de março de 2012.

. Measuring the Atlantic Slave Trade: a Rejoinder. The Journal of African History, Cambridge University Press, Vol. 17, no 4, p. 607-627, 1976c.

. The Import of Firearms into West Africa, 1750-1807: A Quantitative Analysis. The Journal of African History, Cambridge University Press, Vol. 18, no 3, p. 339-368, 1977. 
. Ideology versus the Tirany of Paradigm: Historians and the impact of the Atlantic Slave Trade on African Societies. African Economic History, no 22, p. 37-58, 1994.

. Market Structure and the Profits of the British African Trade in the Late Eighteenth Century. The Journal of Economic History, Vol. 41, no. 4, p. 745-776, dec. 1981.

; ENGERMAN, Stanley L. (ed.). The Atlantic slave trade: effects on economies, societies, and peoples in Africa, the Americas, and Europe. Durham: Duke University Press, 1998.

Africans and the Industrial Revolution in England: A study in the international trade and economic development. Cambridge, UK: Cambridge University Press, 2002.

. Review of David Eltis and David Richardson "Extending the Frontiers: Essays on the New Transatlantic Slave Trade Database". The Journal of Economic History, 71, p. 249-251, 2011.

. English Versus Indian Cotton Textiles: The Impact of Imports on Cotton Textile Production in West Africa. In: RIELLO, Giorgio; TIRTHANKAR, Roy (orgs.). How clothed the world: the world of South Asian textiles, 15001850. Boston, MA: Brill Academic Publishers, 2009, p. 85-114.

; ENGERMAN, Stanley L. Introduction: Gainers and Losers in the Atlantic Slave Trade. In: The Atlantic Slave Trade: Effects on

Economies, Societies, and Peoples in Africa, the Americas, and Europe. Durham; Londres: Duke University Press, 1992.

LOVEJOY, Paul E. The Volume of the Atlantic Slave Trade: a Synthesis. The Journal of African History, vol. 23, no 4, p. 473-501, 1982.

. The Ibadan School and Its Critics. In: JEWSIEWICKI, Bogumil; NEWBURY, David (orgs.). African Historiographies: What History for which Africa. Beverly Hills: Sage, 1983, p. 197-205.

. The African Diaspora: Revisionist Interpretations of Ethnicity, Culture and Religion under Slavery. Studies in the World History of Slavery, Abolition and Emancipation, II, 1. Disponível em: http://www.yorku.ca/nhp/publications/Lovejoy_Studies\%20in\%20 the\%20World\%20History\%20of\%20Slavery.pdf Acesso em: 24 de julho de 2012.

KLEIN, Herbert S. The Atlantic Slave Trade. Cambridge: Cambridge University Press, 1999.

MANTEGA, Guido. Teoria da Dependência Revisitada: um Balanço Crítico. Relatório de Pesquisa, no 27, Rio de Janeiro: FGV, 1997. Disponível em: http://bibliotecadigital.fgv.br/dspace/handle/10438/3003. Acesso em: 16 de janeiro de 2013. 
M’BOKOLO, Elikia. África negra: história e civilizações. Vol. 1: O Séc. XVIII. Lisboa: Colibri, 2007.

MCCLOSKEY, Deirdre N. One More Step: an agreeable reply to Whaples. Historically Speaking, Vol. 11, nº 2, p. 22-23, April 2010.

MORGAN, Kenneth. [Resenha de:] INIKORI, Joseph E. Africans and the Industrial Revolution in England: A Study in International Trade and Economic Development. The Journal of Economic History, Vol. 63, no 3, p. 875876, sep. 2003.

O'BRIEN, Patrick. European Economic Development: The Contribution of the Periphery. The Economic History Review, 35(1), p. 1-18, 1982.

PALMER, Brian D. Velhas posições/Novas necessidades: história, classe e metanarrativa marxista. In: WOOD, Ellen Meiksins; FOSTER, John Bellamy (orgs.). Em defesa da História: marxismo e pós-modernismo. Rio de Janeiro: Jorge Zahar Ed., 1999, p. 74-83.

RICHARDSON, David; BEHRENDT, Stephen D. Inikori's Odyssey: Measuring the British Slave Trade, 1655-1807. Cahiers d'Études Africaines, Vol. 35, no 138/139, p. 599-615, 1995.

RODNEY, Walter. How Europe Underdeveloped Africa. London: Bogle L'ouverture, 1972.

SCHWARZ, Roberto. Um seminário de Marx. In: Seqüências brasileiras. Ensaios. São Paulo: Companhia das Letras, 1999, p. 86-105.

SOLOW, Barbara L. Capitalism and Slavery in the Exceedingly Long Run. In: SOLOW, B; ENGERMAN, Stanley L. (orgs.). British capitalism and Caribbean Slavery. Cambridge: Cambridge University Press, 1987, p. 51-77.

. The Transatlantic Slave Trade: a New Census. The William and Mary

Quarterly Review. Third Series, Vol. 58, no 1, p. 9-16, jan. 2001.

THOMAS, Robert Paul; BEAN, Richard Nelson. The Fishers of Men: The Profits of the Slave Trade, The Journal of Economic History, Vol. 34, .n $n^{0}$, p. 885-914, dez. 1974.

THORNTON, John. A África e os africanos na formação do Mundo Atlântico: 1400-1800. Rio de Janeiro: Campus, 2004.

WILLIAMS, Eric. Capitalismo e escravidão. Traduzido por Carlos Nayfeld. Rio de Janeiro: Americana, 1975.

WOOD, Ellen Meiksins. As origens agrárias do capitalismo. Crítica marxista, no 10, p. 12-29, 2000. 